\title{
Glucose and glucose 6-phosphate as carbon sources in extra- and intracellular growth of enteroinvasive Escherichia coli and Salmonella enterica
}

\author{
Andreas Götz and Werner Goebel† \\ Lehrstuhl für Mikrobiologie, Biozentrum der Universität Würzburg, D-97074 Würzburg, \\ Germany
}

Correspondence

Andreas Götz

agoetz@biozentrum.uni-

wuerzburg.de

Received 17 September 2009

Revised 11 December 2009

Accepted 9 January 2010

\begin{abstract}
To study the role of carbohydrates, in particular glucose, glucose 6-phosphate and mannose, as carbon substrates for extra- and intracellular replication of facultative intracellular enteric bacteria, mutants of two enteroinvasive Escherichia coli (EIEC) strains and a Salmonella enterica serovar Typhimurium isolate were constructed that were defective in the uptake of glucose and mannose ( $\triangle p t s G, \operatorname{man} X Y Z)$, glucose 6-phosphate $(\Delta u h p T)$ or all three carbohydrates ( $\Delta p t s G, \operatorname{man} X Y Z$, $u h p T$ ). The ability of these mutants to grow in RPMI medium containing the respective carbohydrates and in Caco-2 cells was compared with that of the corresponding wild-type strains. In the three strains, deletions of ptsG, $\operatorname{man} X Y Z$ or uhpT resulted in considerably different levels of inhibition of growth in vitro in the presence of glucose, mannose and glucose 6-phosphate, respectively, but hardly reduced their capability for intracellular replication in Caco-2 cells. Even the triple mutants $\triangle p t s G, \operatorname{man} X Y Z$, uhpT of the three enterobacterial strains were still able to replicate in Caco-2 cells, albeit at strain-specific lower rates than the corresponding wild-type strains.
\end{abstract}

\section{INTRODUCTION}

Among the Enterobacteriaceae, Salmonella and Shigella species, as well as the highly related enteroinvasive Escherichia coli (EIEC) strains, are typical intracellular pathogens, capable of survival and active replication in phagocytic (especially macrophages and dendritic) and non-phagocytic (especially epithelial) cells. Infections caused by these intracellular bacterial pathogens are multistep processes with complex metabolic adaptations. Salmonella enterica serovar Typhimurium ( $S$. Typhimurium) and Shigella flexneri (as well as EIEC) are taken up preferentially by consumption of contaminated food and, in the early stages of infection, they encounter varying physico-chemical and nutritional conditions in the gut before they reach their intracellular compartments. In this early stage of infection, the bacteria grow mainly extracellularly under anoxic or microaerobic conditions

†Present address: Max-von-Pettenkofer Institut, Ludwig-MaximilianUniversität München, D-80336 München, Germany.

Abbreviations: $\mathrm{CCR}$, carbon catabolite repression; EIEC, enteroinvasive Escherichia coli; FCS, fetal calf serum; Glc, glucose; Glc6P, glucose 6phosphate; LB, Luria-Bertani; Man, mannose; PEP, phosphoenolpyruvate; p.i., post-infection; PTS, phosphoenolpyruvate: carbohydrate phosphotransferase system; SCV, Salmonella-containing vacuole; TSB, tryptic soy broth. and growth may be supported by qualitatively and quantitatively changing nutrients.

Salmonella and Shigella cross the intestinal barrier by entering and transcytosing M-cells in the Peyer's patches (Vazquez-Torres \& Fang, 2000). After reaching the underlying extracellular matrix these bacteria are taken up by phagocytic cells, i.e. dendritic cells, monocytes/ macrophages or granulocytes.

Shigella triggers fast apoptosis of the infected phagocytic host cells. The released bacteria subsequently invade epithelial cells in the gut from the basolateral site. Within the gut epithelium, Shigella multiplies intracellularly and spreads to neighbouring cells throughout infection, thereby destroying large parts of the infected tissue (Phalipon \& Sansonetti, 2007).

$S$. Typhimurium, sometimes in infected humans and more generally in the mouse model, becomes systemic by spreading into different peripheral organs mainly via infected phagocytes (dendritic cells, monocytes/macrophages).

In infected phagocytic and non-phagocytic host cells, Shigella (and EIEC) escapes from the primary phagosome into the cytosol where these pathogens actively replicate. By contrast, $S$. Typhimurium remains mainly in a specifically modified phagosomal compartment, the Salmonella- 
containing vacuole (SCV) (Brumell \& Grinstein, 2004). Recent reports (Beuzón et al., 2000, 2002) suggest, however, that even $S$. Typhimurium may survive and multiply in the cytosol of some host cells under special conditions.

The genomes of Shigella/EIEC (Jin et al., 2002) and S. Typhimurium (Bell et al., 2004; McClelland et al., 2001) contain complete gene sets for all major catabolic and anabolic pathways - typical for prototrophic/heterotrophic micro-organisms. In accord with their genetic potential, these pathogens are able to grow in defined minimal media supplemented with a single suitable carbon source.

Glucose (Glc) is a preferred carbon source for in vitro growth. In E. coli K-12, up to 14 phosphoenolpyruvate: carbohydrate phosphotransferase systems (PTS) were identified as transporters for different carbohydrates. Six of these PTS, encoded by the genes ptsG/crr, manXYZ, fruBA, malX/crr, scrA/crr and $b g l F$ (reviewed by Postma et al., 1993), were reported to accept Glc as substrate. These genes are also present in the genomes of Shigella/EIEC (Jin et al., 2002) and some of them in part are also modified in S. Typhimurium (Bell et al., 2004; McClelland et al., 2001). PtsG represents the major Glc-specific PTS permease in $E$. coli K-12 (and in many other heterotrophic bacteria) with the highest affinity for Glc among these systems.

Glucose 6-phosphate (Glc6P) is taken up by both pathogens via the UhpT transporter. The uhpT gene of Shigella/EIEC and S. Typhimurium is under the control of a complex two-component system (uhpABC) (Verhamme et al., 2002) and of carbon catabolite repression (CCR). Hence, expression of UhpT is low in the presence of Glc.

Shigella/EIEC and S. Typhimurium also have the metabolic gene setting for catabolizing a large variety of other carbon substrates, including $\mathrm{C}_{2^{-}}, \mathrm{C}_{3^{-}}, \mathrm{C}_{4^{-}}$and $\mathrm{C}_{5}$-substrates, which may be eventually provided by the host cells as carbon substrates for intracellular bacterial growth. $S$. Typhimurium contains an additional $55 \mathrm{~kb}$ large gene cluster carrying all $p d u$ genes for propanediol degradation and those for vitamin $\mathrm{B}_{12}$ biosynthesis and ethanolamine utilization (Klumpp \& Fuchs, 2007).

To obtain insights into the intracellular metabolism of the two pathogens, we constructed mutants of two EIEC strains and an $S$. Typhimurium isolate with deletions in $p t s G$, manXYZ and/or uhpT and studied their growth relative to the corresponding wild-type strains in defined culture media and in Caco- 2 cells. These mutants were also recently used for determining the intracellular carbon metabolism by ${ }^{13} \mathrm{C}$-isotopologue profiling (A. Götz and other authors, unpublished data).

\section{METHODS}

Bacterial strains, cell line and plasmids. EIEC 4608-58 and EIEC HN280 were gifts from P. Sansonetti (Institut Pasteur, Paris, France) and M. Nicoletti (Dipartimento di Scienze Biomediche, Università G. D'Annunzio, Chieti, Italy). S. Typhimurium (Stm) 14028s was obtained from M. Hensel (Mikrobiologisches Institut, Universitätsklinikum Erlangen, Germany). E. coli K-12 (DSM 498) and the Caco-2 cell line (ACC 169) were obtained from the DSMZ. pBR322 was obtained from New England Biolabs. All strains and mutants described in this study are listed in Table 1.

Construction of mutants. Bacteria were routinely cultured at 30 or $37^{\circ} \mathrm{C}$ in Luria Broth [LB; $10 \mathrm{~g}$ tryptone $1^{-1}$ (Oxoid), 5 g Bacto yeast extract $\mathrm{l}^{-1}$ (BD Biosciences), $5 \mathrm{~g} \mathrm{NaCl}^{-1}$ ] with shaking or on $\mathrm{LB}$ agar $\left(13 \mathrm{~g} \mathrm{l}^{-1}\right)$. If needed, antibiotics and other supplements were added to the following final concentrations: $100 \mu \mathrm{g}$ ampicillin $\mathrm{ml}^{-1}, 30 \mu \mathrm{g}$ chloramphenicol $\mathrm{ml}^{-1}, 50 \mu \mathrm{g}$ kanamycin $\mathrm{ml}^{-1}, 0.2 \%(\mathrm{w} / \mathrm{v}) \mathrm{L}-$ arabinose. In addition, all constructed EIEC mutants were plated on tryptic soy broth (TSB) agar [30 $\mathrm{g} \mathrm{l}^{-1}$ (Sigma, contains 2 g glucose $\left.1^{-1}\right)$ ] supplemented with $0.01 \%(\mathrm{w} / \mathrm{v})$ Congo red and incubated at $37{ }^{\circ} \mathrm{C}$ to test their ability to bind the pigment Congo red. Only red colonies were used for further studies.

Mutant strains were generated as described by Datsenko \& Wanner (2000). Oligonucleotides used to amplify the chloramphenicol- or kanamycin-resistance cassette from pKD3 or pKD4, respectively, using iProof-polymerase from Bio-Rad are listed in Table 2 (65-mers). Annealing temperature was varied between 55 and $65{ }^{\circ} \mathrm{C}$. Colonies were screened for correct insertion of the resistance cassette by PCR using MolTaq-polymerase from Molzym according to the manufacturer's instruction. Oligonucleotides are listed in Table 2 (20-mers).

For EIEC/K-12 the following genes were deleted: $u h p T$ from aa 6 to 461 , $p t s G$ from aa 6 to 474 and manXYZ from aa 2 of $\operatorname{manX}$ to 282 of manZ. For Stm 14028s, uhpT was deleted from aa 3 to 459 , pts $G$ from aa 4 to 474 , manXYZ from aa 4 of $\operatorname{man} X$ to 274 of $m a n Z$ and $g l k$ from aa 4 to 319 .

Complementation of EIEC 4608-58. For complementation experiments, the coding sequence of $u h p T$ of EIEC 4608-58 was reverse-cloned into the BamHI/SgrAI restriction site of pBR322 using primer uhpTcomp-up-1 and uhpT-comp-down-1 (Tables 1 and 2, 30-mers). pts $G$ was reverse-cloned into the SalI restriction site of pBR322 using primer ptsGcomp-up and ptsG-comp-down and manXYZ was cloned into the EcoRI site of pBR322 using primer manXYZ-comp-up and manXYZ-compdown. Transcription of all genes was initiated at their own promoters.

Growth in minimal medium on different sugars. Cell culture medium RPMI 1640 with $2 \mathrm{mM}$ L-glutamine (Gibco) was used as minimal medium. Carbon sources were added to a final concentration of $10 \mathrm{mM}$. For growth curves, bacteria from an overnight culture in TSB (EIEC) or LB (Salmonella) were washed twice with PBS, diluted $1: 100$ in minimal medium and further incubated at $37{ }^{\circ} \mathrm{C}$ with shaking. Cell density was determined every hour by $\mathrm{OD}_{600}$ measurement.

$\boldsymbol{\beta}$-Galactosidase test. The status of CCR was determined by the activity of the $\beta$-galactosidase enzyme. For this goal, an overnight culture was diluted $1: 100$ in fresh TSB supplemented with $5 \mathrm{mM}$ lactose and further shaken for $2 \mathrm{~h}$ at $37{ }^{\circ} \mathrm{C}$ until $\mathrm{OD}_{600} \approx 1$. An aliquot of $10^{9}$ bacteria was pelleted by centrifugation and resuspended in $1 \mathrm{ml}$ $\mathrm{Na}^{+} / \mathrm{K}^{+}$-phosphate buffer $(0.05 \mathrm{M}, \mathrm{pH}$ 7.4). Bacteria were lysed by incubation with $50 \mu \mathrm{l}$ toluene and $50 \mu \mathrm{l}$ sodium deoxycholate $(1 \%)$ at $37{ }^{\circ} \mathrm{C}$ for $30 \mathrm{~min}$. $\beta$-Galactosidase activity was determined at $37^{\circ} \mathrm{C}$ by mixing $50 \mu \mathrm{l}$ cell lysate with $950 \mu \mathrm{l} \mathrm{Na}{ }^{+} / \mathrm{K}^{+}$-phosphate buffer and $100 \mu \mathrm{l}$ ONPG $\left(5 \mathrm{mg} \mathrm{ml}^{-1}\right)$. The reaction was stopped after $15 \mathrm{~min}$ by adding $40 \mu \mathrm{la}_{2} \mathrm{CO}_{3}(10 \%)$ and $\mathrm{OD}_{420}$ was measured. Protein concentration of the cell lysate was determined by Bradford assay and the specific activity of $\beta$-galactosidase was calculated as $\mu \mathrm{mol} \mathrm{min}{ }^{-1}$ $(\mathrm{mg} \text { protein })^{-1}$. Statistical significance was determined with Student's unpaired $t$-test; $P<0.05$ was considered to be significant.

Bacterial growth conditions prior to infection. EIEC strains were cultured overnight in $20 \mathrm{ml} \mathrm{TSB}$ at $30{ }^{\circ} \mathrm{C}$ and then diluted $1: 100$ in 
Table 1. Bacterial strains and plasmids used in this study

\begin{tabular}{|c|c|c|}
\hline Strain/plasmid & Genotype and property & Reference/source \\
\hline \multicolumn{3}{|c|}{ E. coli $\mathrm{K}-12$ strain } \\
\hline $\mathrm{K}-12$ & Wild-type & DSMZ (DSM 498) \\
\hline AG044 & $\mathrm{K}-12 \Delta u h p T$; sugar phosphate antiporter & This study \\
\hline AG098 & K-12 $\Delta p t s G$; glucose-specific PTS enzyme IICB & This study \\
\hline \multicolumn{3}{|l|}{ EIEC strain } \\
\hline $4608-58$ & Wild-type, lactose ${ }^{+}$ & Sansonetti et al. (1982) \\
\hline AG069 & $4608-58 \Delta u h p T$ & This study \\
\hline AG096 & $4608-58 \Delta p t s G$ & This study \\
\hline AG161 & 4608-58 $\Delta$ manXYZ; mannose-specific PTS enzyme IIAB, IIC and IID & This study \\
\hline AG097 & $4608-58 \Delta p t s G, u h p T$ & This study \\
\hline AG157 & 4608-58 $\Delta p t s G, \operatorname{manXYZ}$ & This study \\
\hline AG135 & 4608-58 $\Delta p t s G, \operatorname{manXYZ,~uhpT~}$ & This study \\
\hline HN280 & Wild-type, lactose ${ }^{-}$ & Nicoletti et al. (1988) \\
\hline AG136 & $\mathrm{HN} 280 \Delta u h p T$ & This study \\
\hline AG166 & $\mathrm{HN} 280 \Delta p t s G$ & This study \\
\hline AG158 & HN280 $\Delta \operatorname{manXYZ}$ & This study \\
\hline AG167 & $\mathrm{HN} 280 \Delta p t s G, u h p T$ & This study \\
\hline AG168 & $\mathrm{HN} 280 \Delta p t s G, \operatorname{man} X Y Z$ & This study \\
\hline AG169 & HN280 $\Delta p t s G, \operatorname{manXYZ,~uhpT~}$ & This study \\
\hline \multicolumn{3}{|c|}{$S$. Typhimurium strain } \\
\hline $14028 \mathrm{~s}$ & Wild-type & ATCC14028s \\
\hline AG046 & $14028 \mathrm{~s} \Delta u h p T$ & This study \\
\hline AG088 & 14028s $\Delta p t s G$ & This study \\
\hline AG094 & $14028 \mathrm{~s} \Delta p t s G, u h p T$ & This study \\
\hline AG223 & $14028 \mathrm{~s} \Delta p t s G, \operatorname{manXYZ}$ & This study \\
\hline AG143 & 14028s $\Delta p t s G, \operatorname{manXYZ,~uhpT~}$ & This study \\
\hline AG229 & $14028 \mathrm{~s} \Delta g l k$ & This study \\
\hline AG230 & 14028s $\Delta p t s G, \operatorname{manXYZ,glk}$ & This study \\
\hline \multicolumn{3}{|c|}{ 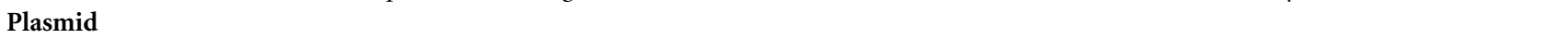 } \\
\hline pKD3 & Template plasmid contains chloramphenicol-resistance cassette, $\mathrm{Amp}^{\mathrm{R}}, \mathrm{Cm}^{\mathrm{R}}$ & Datsenko \& Wanner (2000) \\
\hline pKD4 & Template plasmid contains kanamycin-resistance cassette, $\mathrm{Amp}^{\mathrm{R}}$, $\mathrm{Kan}^{\mathrm{R}}$ & Datsenko \& Wanner (2000) \\
\hline pKD46 & Temperature-sensitive plasmid contains phage $\lambda$ red recombinase system, $A_{m p}{ }^{R}$ & Datsenko \& Wanner (2000) \\
\hline pCP20 & Temperature-sensitive plasmid contains FLP recombinase gene, $\mathrm{Amp}^{\mathrm{R}}, \mathrm{Cm}^{\mathrm{R}}$ & Datsenko \& Wanner (2000) \\
\hline pBR322 & Cloning vector, $A m p^{R}, T c^{R}$ & $\begin{array}{l}\text { Bolivar et al. (1992), Covarrubias } \\
\text { et al. (1981), New England Biolabs }\end{array}$ \\
\hline pAG078 & $\begin{array}{l}\text { Derivate of pBR322 containing } \mathrm{P}_{u h p T^{-}} \text {uhpT of EIEC 4608-58 expressed from } \\
\text { its native promoter reverse-cloned into BamHI/SgrAI restriction site, } \mathrm{Amp}^{\mathrm{R}}\end{array}$ & This study \\
\hline pAG119 & $\begin{array}{l}\text { Derivate of pBR322 containing } \mathrm{P}_{p t s G}-p t s G \text { of EIEC } 4608-58 \text { expressed from } \\
\text { its native promoter reverse-cloned into SalI restriction site, } \mathrm{Amp}^{\mathrm{R}}\end{array}$ & This study \\
\hline pAG124 & $\begin{array}{l}\text { Derivate of pBR322 containing } \mathrm{P}_{\operatorname{man} X Y Z}-\operatorname{manXYZ} \text { of EIEC } 4608-58 \text { expressed } \\
\text { from its native promoter cloned into EcoRI restriction site, } \mathrm{Amp}^{\mathrm{R}}, \mathrm{Tc}^{\mathrm{R}}\end{array}$ & This study \\
\hline
\end{tabular}

$20 \mathrm{ml}$ fresh TSB and further incubated for $2 \mathrm{~h}$ at $37{ }^{\circ} \mathrm{C}$ with aeration. An overnight culture of Stm 14028s grown in $20 \mathrm{ml} \mathrm{LB}$ with $0.5 \%$ $\mathrm{NaCl}$ at $37{ }^{\circ} \mathrm{C}$ was diluted $1: 100(\mathrm{v} / \mathrm{v})$ into $20 \mathrm{ml}$ fresh LB with $1 \%$ $\mathrm{NaCl}$ and further shaken for $2.5 \mathrm{~h}$ at $37^{\circ} \mathrm{C}$. When cultures reached late exponential growth phase $\left(\mathrm{OD}_{600} \approx 1\right)$, bacteria were diluted in RPMI 1640 containing $10 \%$ fetal calf serum (FCS) and added to the Caco-2 cells at different m.o.i. (see below).

Adhesion assays. Caco- 2 cells were cultured in RPMI 1640 with $2 \mathrm{mM} \mathrm{L}$-glutamine and $10 \mathrm{mM}$ glucose supplemented with $10 \%$ heat-inactivated FCS (Biochrom). Before infection, cells were seeded into 24 -well plates at a density of $10^{5}$ cells well $^{-1}$ and grown for 2 days to $90 \%$ confluence.

Adhesion of the bacteria to Caco-2 cells was investigated by using cytochalasin $\mathrm{D}$ to destroy the actin cytoskeleton and inhibit bacterial cell invasion in an actin-dependent manner. Therefore, the cells were incubated with fresh RPMI containing $10 \%$ FCS and $1 \mu \mathrm{g}$ cytochalasin $\mathrm{D} \mathrm{ml} \mathrm{m}^{-1} 30 \mathrm{~min}$ before starting the infection. Then bacteria were added at a constant m.o.i. of 17 and allowed to adhere for $1 \mathrm{~h}$ in the presence of $1 \mu \mathrm{g}$ cytochalasin $\mathrm{D} \mathrm{ml}^{-1}$ without centrifugation. After this, cells were washed six times with RPMI containing $10 \%$ FCS and $1 \mu \mathrm{g}$ cytochalasin $\mathrm{D} \mathrm{ml}^{-1}$ to remove nonadherent bacteria. To count the number of adherent bacteria, cells were washed once with ice-cold PBS and lysed with ice-cold distilled water to detach the bacteria. A serial dilution was plated on LB agar.

Statistical significance was determined with Student's unpaired $t$-test; $P<0.05$ was considered to be significant.

Invasion and replication assay. Cells were prepared as described above 2 days before infection. Bacteria were diluted in RPMI with 
Table 2. Oligonucleotides used in this study

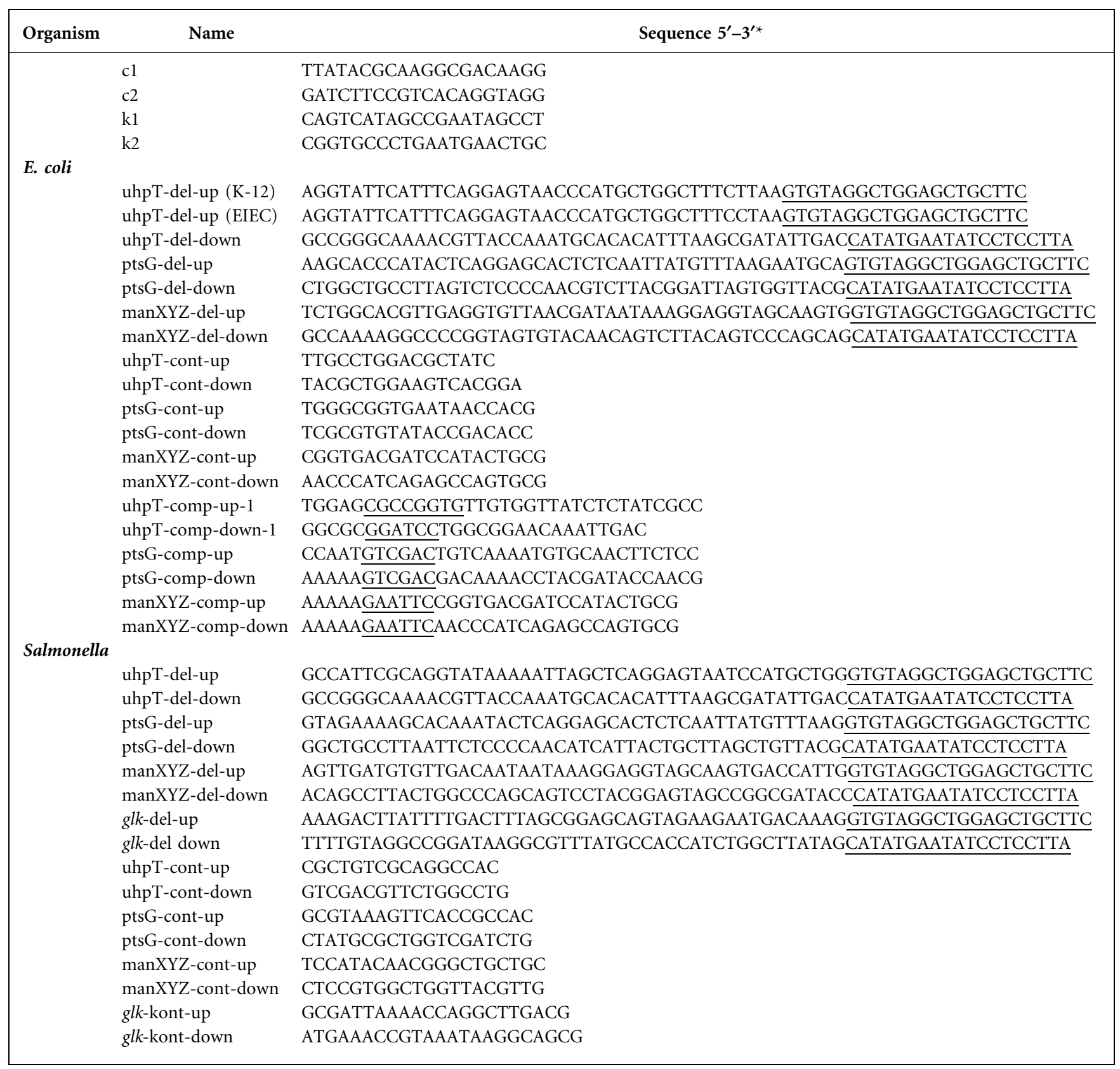

${ }^{\star}$ Restriction sites and primer sites are underlined.

$10 \%$ FCS (or without where indicated) and added to the cells at a constant m.o.i. of 17 for invasion assays and at a different m.o.i. (as indicated) to achieve similar numbers of c.f.u. at $1 \mathrm{~h}$ post-infection (p.i.) for replication assays. Infected cells were centrifuged at $173 \mathrm{~g}$ and $37^{\circ} \mathrm{C}$ for $5 \mathrm{~min}$ to synchronize invasion and bacteria were allowed to invade the cells for $45 \mathrm{~min}$ (EIEC) or $60 \mathrm{~min}$ (Salmonella). Then, the bacteria-containing medium was replaced by RPMI containing $10 \% \mathrm{FCS}$ and $100 \mu \mathrm{g}$ gentamicin $\mathrm{ml}^{-1}$ to kill extracellular bacteria. This was defined as time point $0 \mathrm{~h}$ p.i. After $1 \mathrm{~h}$, gentamicin concentration was decreased to $20 \mu \mathrm{g} \mathrm{ml}^{-1}$. At defined time points p.i., the gentamicin-containing medium was removed, cells were washed with ice-cold PBS and lysed with ice-cold distilled water. The c.f.u. was determined by plating a serial dilution on LB agar.

\section{RESULTS}

\section{Glucose uptake of EIEC strains depends mainly on two major PTS permeases}

For this study we used two different clinical EIEC isolates, EIEC 4608-58 (Sansonetti et al., 1982) and EIEC HN280 (Nicoletti et al., 1988), which belong to different phylogenetic groups of $E$. coli based on the criteria described by Clermont et al. (2000). EIEC 4608-58 is $c h u A^{+}, y j a^{-}, \mathrm{TspE} \mathrm{C}^{-}{ }^{-}$, which is characteristic for members of the phylogenetic group D strains, whereas 
EIEC HN280 is $\mathrm{chuA}^{-}, \mathrm{yja}^{-}$, TspE4.C2 ${ }^{-}$, which is characteristic for group A strains.

The two EIEC strains multiplied in RPMI 1640 containing $10 \mathrm{mM}$ Glc with similar generation times $(48 \pm 0.2$ and $49 \pm 1 \mathrm{~min}$, respectively) to $E$. coli $\mathrm{K}-12(46 \pm 0.5 \mathrm{~min})$, taken as a control (Fig. 1). To obtain Glc-uptake mutants of both EIEC strains, we first deleted $p t s G$ encoding EIICB of the major Glc-specific PTS permease of E. coli K-12 (Stock et al., 1982). The resulting $\Delta p t s G$ mutants grew - as expected - more slowly with Glc. The increase in doubling times was, however, less significant for the two EIEC $\Delta p t s G$ mutants $(70 \pm 1 \mathrm{~min}$ for EIEC $4608-58$ and $89 \pm 1 \mathrm{~min}$ for EIEC
HN280) than for the E. coli K-12 mutant (133 $\pm 1 \mathrm{~min}$ ), suggesting that an additional Glc uptake system(s) is more efficient in the EIEC strains than in E. coli K-12. Growth of the mutants in the presence of mannose (Man) or Glc6P was not altered compared to the wild-type strains (data not shown).

Next, manXYZ, which encodes EIIAB, IIC and IID of the major PTS ${ }^{\mathrm{Man}}$, but is also able to transport Glc (Erni \& Zanolari, 1985; Erni et al., 1987; Postma et al., 1993), was deleted in both EIEC wild-type strains and their $\Delta p t s G$ mutants. The $\triangle \operatorname{man} X Y Z$ mutants grew with identical doubling times to the wild-type strains on Glc and Glc6P but much more slowly on Man (not shown). However,
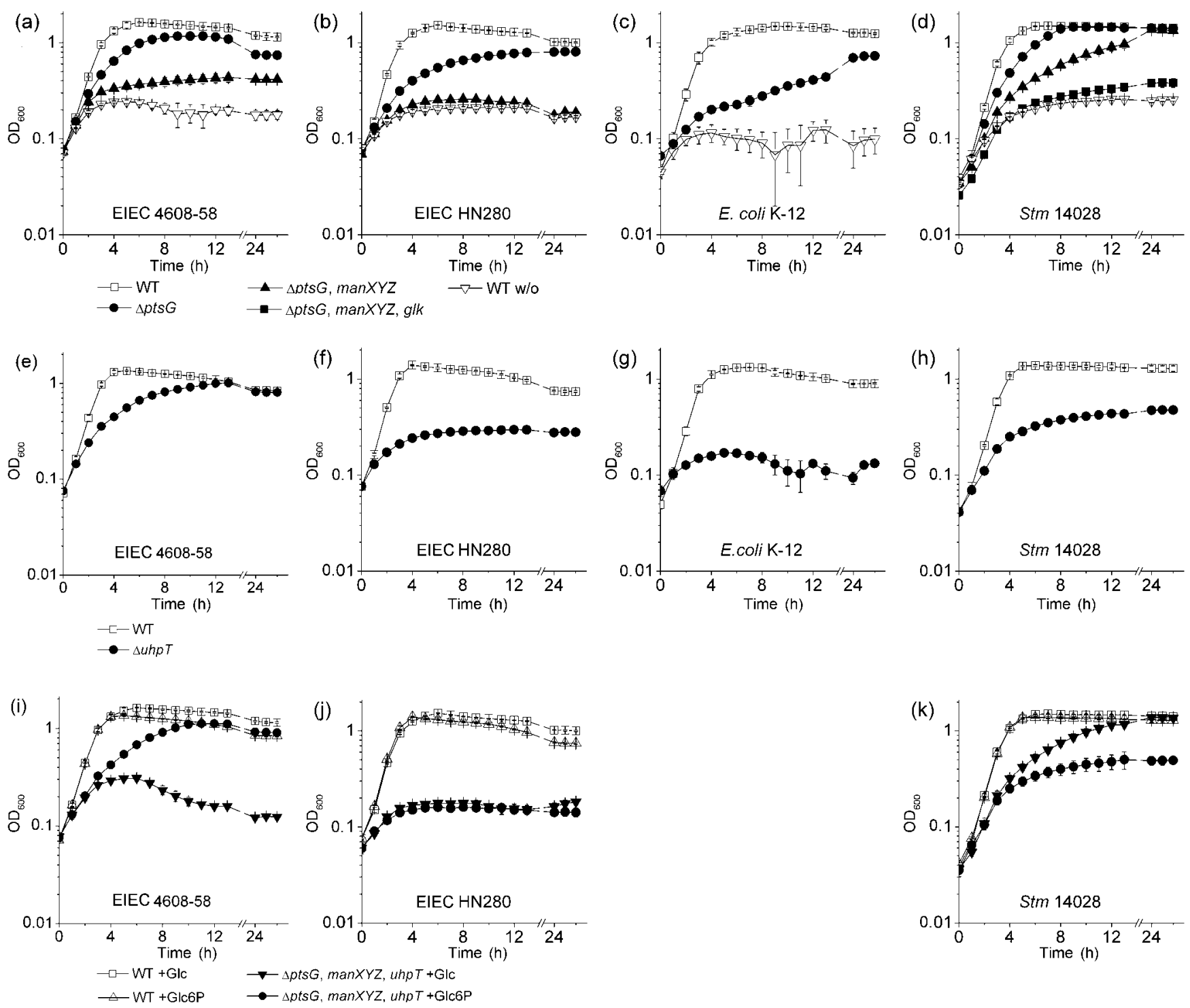

Fig. 1. Growth of EIEC 4608-58 (a, e, i), EIEC HN280 (b, f, j), E. coli K-12 (c, g) and Stm 14028s (d, h, k) wild-type strains (WT) and their Glc- and/or Glc6P-uptake mutants in RPMl 1640 with 10 mM Glc (a, b, c, d, i, j, k) or Glc6P (e, f, g, h, i, j, k). As a control, growth of the WT in RPMl 1640 medium without carbohydrate (w/o) is shown. Generation times were calculated during exponential growth in the first $3 \mathrm{~h}$. Generation times given in the text and on the figure are mean values $\pm S D$ of three independent experiments. 
growth of the $\Delta p t s G, \operatorname{manXYZ}$ mutants of both EIEC strains (and E. coli K-12, data not shown) in the presence of $10 \mathrm{mM}$ Glc was very low (Fig. 1a, b). The $\Delta p t s G$, manXYZ mutant of strain 4608-58 showed some residual growth with $10 \mathrm{mM}$ Glc (reaching an $\mathrm{OD}_{600}$ of 0.4 after $13 \mathrm{~h}$ ) but not with $2 \mathrm{mM} \mathrm{Glc}$, suggesting an additional low-affinity Glc transport system(s) in this strain.

Growth of the $\Delta p t s G, \operatorname{man} X Y Z$ mutants in the presence of $10 \mathrm{mM}$ Glc6P was as efficient as that of the wild-type strains, while growth in the presence of $10 \mathrm{mM}$ Man was as low as observed with the $\triangle$ manXYZ mutants (not shown).

\section{The phenotype of the uhpT deletion mutants of the two EIEC strains is different}

The two EIEC wild-type strains grew equally well in RPMI medium containing $10 \mathrm{mM}$ Glc6P as did E. coli K-12 (Fig. 1e, f, g). The $\Delta u h p T$ mutants of EIEC HN280 and E. coli K-12 were unable to replicate in the presence of $10 \mathrm{mM}$ Glc6P, indicating that UhpT is the only transporter for Glc6P in these strains (Fig. 1f, g). However, the corresponding $\Delta u h p T$ mutant of EIEC 4608-58 was still able to grow under these conditions, albeit at an elevated generation time $(81 \pm 0.4 \mathrm{~min})$ compared to that of the wild-type strain ( $48 \pm 1 \mathrm{~min})$ (Fig. 1e).

A $u h p T$ gene duplication in this EIEC strain could be ruled out by Southern blot analyses. Using two different probes comprising nt 50-622 and 216-1179 of the uhpT coding sequence, a single hybridizing band was detected with each probe in EcoRI-restricted genomic DNA of the wild-type strain, which was missing in the $\Delta u h p T$ mutant (data not shown).

Since recent reports (Schwoppe et al., 2002, 2003) showed that the Glc6P sensor UhpC is also able to transport Glc6P in the absence of UhpT, we deleted $u h p C$ in the EIEC 460858 wild-type strain and its $\Delta u h p T$ mutant. However, this deletion did not alter growth of these two strains in the presence of $10 \mathrm{mM}$ Glc6P.
GlpT, the glycerol-3-phosphate antiporter, and PgtP, a putative phosphoenolpyruvate (PEP) transporting protein (Johnson et al., 2007; Welch et al., 2002) that shows sequence similarity with UhpT, were also tested for their ability to function as an additional Glc6P transporter in EIEC $4608-58$ by deleting these genes. However, deletion of none of these genes in the wild-type strain or the $\Delta u h p T$ mutant affected Glc6P transport. As expected, uhpT mutants of both EIECs grew similarly to the wild-type strains in the presence of 2 and $10 \mathrm{mM}$ Glc or Man (data not shown).

\section{In vitro growth of EIEC mutants deficient in the major GIc and GIc6P uptake systems in the presence of GIc and/or GIc6P}

Deletion of $p t s G, \operatorname{manXYZ}$ and $u h p T$ abolished growth of EIEC HN280 completely in the presence of $10 \mathrm{mM} \mathrm{Glc}$ and Glc6P (Fig. 1j) as well as Man. The $\Delta p t s G$, manXYZ, uhpT mutant of EIEC 4608-58 grew more slowly and reached a lower cell density in Glc- (and Man-) containing RPMI 1640 medium than the $\Delta p t s G$, manXYZ mutant (Fig. 1i) due to partial autolysis, which occurred even in TSB (not shown).

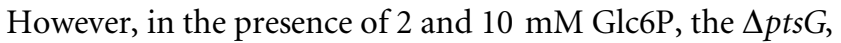
manXYZ, uhpT mutant still replicated with the same generation time as the $\Delta u h p T$ mutant (Fig. 1i). This result rules out the possibility that an extracellular phosphatase(s) hydrolysing Glc6P to Glc may be responsible for the residual growth of the $\Delta u h p T$ mutant with Glc6P.

The growth defects of the $\Delta p t s G$, manXYZ, uhpT mutant of EIEC 4608-58 in RPMI medium with Glc, Man and Glc6P could be restored by trans-complementation with the plasmids pAG119 (carrying $\mathrm{P}_{p t s}-$ pts $G$ ), pAG124 (carrying

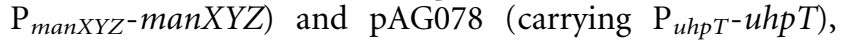
respectively. Replication of the $\Delta p t s G$, manXYZ, uhpT mutant reached almost wild-type levels in the presence of Glc and Glc6P when complemented with pAG119 and pAG078, respectively (Fig. 2a, c), while pAG124 restored growth of the $\Delta p t s G, \operatorname{manXYZ}, u h p T$ mutant to a level
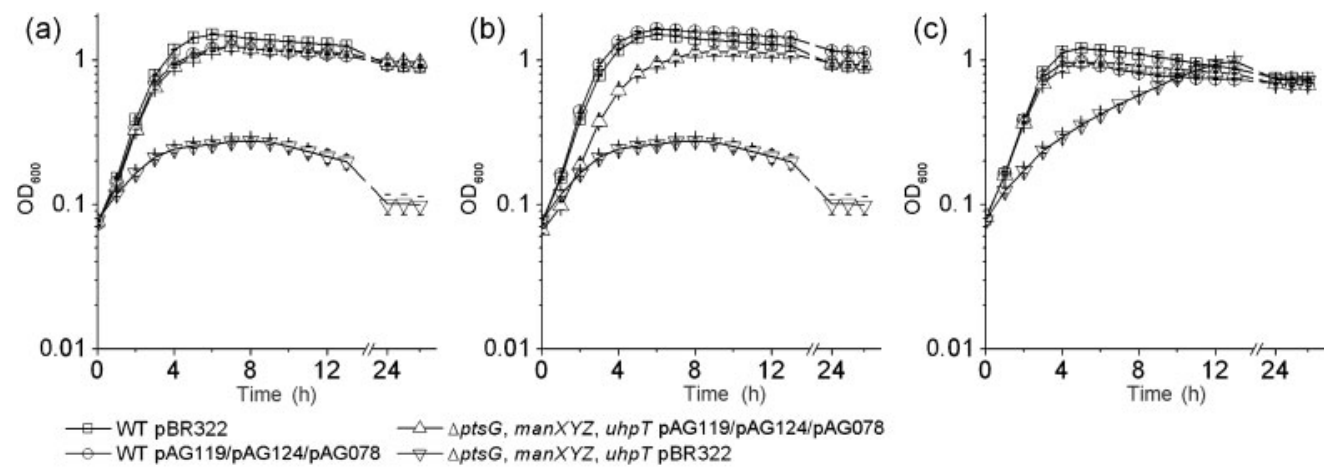

Fig. 2. Complementation of EIEC 4608-58 $\Delta p t s G$, $\operatorname{man} X Y Z$, uhpT. The Glc/Glc6P-uptake mutant of EIEC 4608-58 was trans-

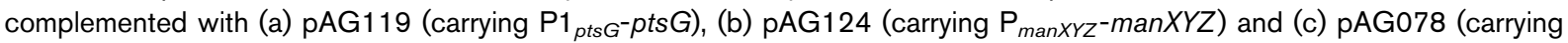
$\mathrm{P}_{\text {uhpT }}$-uhpT), as described in Methods. The trans-complemented strains were grown in RPMl 1640 with $10 \mathrm{mM}$ Glc $(\mathrm{a}, \mathrm{b})$ or Glc6P (c). The WT and mutant strains transformed with the pBR322 vector alone were used as controls. 
similar to that of the $\Delta p t s G$ mutant in the presence of Glc (Fig. 2b).

\section{Growth properties of $S$. Typhimurium mutants with deletions in $\triangle p t s G, \operatorname{man} X Y Z$ and/or glk or uhpT}

We also introduced similar deletions as described for the two EIEC strains into S. Typhimurium 14028s. This wildtype strain (abbreviated as Stm 14028s) grew on Glc or Glc6P with generation times of about $40 \pm 2$ min (Fig. 1d and $\mathrm{h}$ ). The $p t s G$ deletion led to a doubling time of $53 \pm 1 \mathrm{~min}$ in the presence of $10 \mathrm{mM}$ Glc (Fig. 1d) but did not affect growth on Glc6P or Man.

Deleting manXYZ inhibited growth on $10 \mathrm{mM}$ Man but not on Glc or Glc6P (not shown). The $\Delta p t s G$, manXYZ mutant did not grow on Man and grew more slowly on Glc (generation time $63 \pm 1 \mathrm{~min}$ ) than the wild-type strain and the $\Delta p t s G$ mutant, whereas growth on Glc6P was unaffected. However, in contrast with the corresponding EIEC mutants, the $\Delta p t s G$ and $\Delta p t s G, \operatorname{manXYZ}$ mutants of Stm 14028s reached a similar cell density in Glc-containing RPMI during the stationary phase to the wild-type (Fig. 1d) even if the concentration was lowered to $2 \mathrm{mM}$. This suggests that other glucose-transporting PTS or other non-PTS glucose transporters, e.g. GalP and MglABC (Death \& Ferenci, 1993; Postma, 1977), are active in these mutants. This was confirmed by deleting glk encoding a glucokinase, which phosphorylates glucose that is taken up by these non-PTS systems (Meyer et al., 1997). The resulting $\triangle p t s G$, manXYZ, glk mutant showed a strong growth reduction in RPMI with $10 \mathrm{mM}$ Glc (Fig. 1d), whereas the deletion of $g l k$ alone had no effect (not shown).

The $u h p T$ deletion strongly reduced growth in the presence of Glc6P (Fig. 1h) without affecting growth on Glc or Man. The $\Delta p t s G$, manXYZ, uhpT mutant was unable to grow on Glc6P or Man as expected but could still grow on Glc with a doubling time similar to the $\Delta p t s G$, manXYZ mutant (Fig. 1k).

\section{Growth of the two EIEC strains and Stm 14028s on $\mathrm{C}_{3}$-substrates}

Recently, it was shown that glycerol and possibly other $\mathrm{C}_{3^{-}}$substrates may serve as preferred carbon sources for intracellular growth of Listeria monocytogenes (Eylert et al., 2008). We therefore also tested the growth capacity of the EIEC strains, the Stm 14028s isolate and the generated carbohydrate uptake mutants on various $\mathrm{C}_{3}$-substrates.

All wild-type strains and their $\Delta p t s G$, manXYZ, uhpT mutants were able to grow on $10 \mathrm{mM}$ glycerol, lactate or pyruvate. As shown in Fig. 3 (for EIEC 4608-58 as an example), all wildtype strains and mutants grew on these substrates with generation times ranging from 60 to $70 \mathrm{~min}$. The highest bacterial density was always reached in RPMI medium with a carbon source of glycerol, followed by lactate and pyruvate.

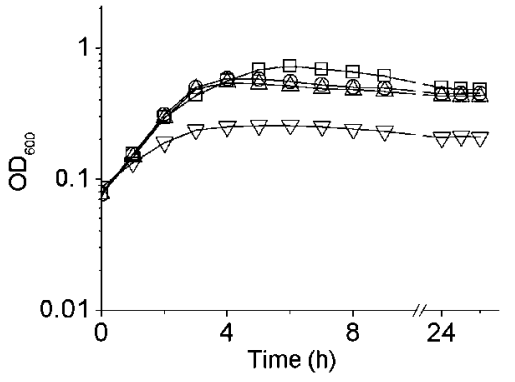

Fig. 3. Growth of EIEC 4608-58 WT on different $\mathrm{C}_{3}$-substrates at $10 \mathrm{mM}$; similar results to those shown here for EIEC 4608-58 WT were also found for the other two WT strains and the mutants. Glycerol, $\square$; lactate, $\bigcirc$; pyruvate, $\triangle$; without substrate, $\nabla$.

Interestingly, the $\Delta p t s G, \operatorname{man} X Y Z$, uhpT mutant of EIEC 4608-58 no longer exhibited autolysis when growing in the presence of either of these $\mathrm{C}_{3}$-substrates or on sugars other than Glc or Man.

\section{Carbohydrate-uptake mutants of the two EIEC strains and of Stm 14028s show altered adhesion, invasion and intracellular replication rates in Caco-2 cells}

To test the influence of the defects in Glc and Glc6P uptake on the intracellular growth cycle of the analysed enterobacterial pathogens, we compared adhesion, internalization and intracellular generation times of the above-described mutants (determined as described in Methods) to those of the corresponding wild-type strains, using epithelial colorectal adenocarcinoma (Caco-2) cells as host cells.

As shown in Fig. 4 (EIEC 4608-58) and Table 3 (EIEC HN280 and Stm 14028s), the rates of internalization of the bacteria by Caco- 2 cells correlated in general with their adhesion efficiencies to these human cells. EIEC 4608-58 was about fivefold less adherent and invasive than EIEC HN280. However, a significant increase in adherence and invasiveness was observed with the $\Delta p t s G$ mutant as well as with the $\Delta p t s G$, manXYZ and $\Delta p t s G$, manXYZ, uhpT mutants of EIEC 4608-58. CCR is partially relieved due to the $\Delta p t s G$ mutation as indicated by a more than 10 -fold increase of the $\beta$-galactosidase activity of the $\Delta p t s G$ mutants (Fig. 4). Thus, there might be a connection between the relaxed CCR and the increased adherence and subsequent internalization of the $\Delta p t s G$ mutants of EIEC 4608-58.

Only a slight increase in adherence and invasiveness was observed in the $\Delta p t s G$ mutant of EIEC HN280 but the $\Delta p t s G$, manXYZ and $\Delta p t s G, \operatorname{manXYZ}$, uhpT mutants showed a sharp drop in both properties. No significant difference in adhesion and invasiveness was observed between the Stm 14028s wild-type strain and the Glc and Glc6P uptake mutants (Table 3). 


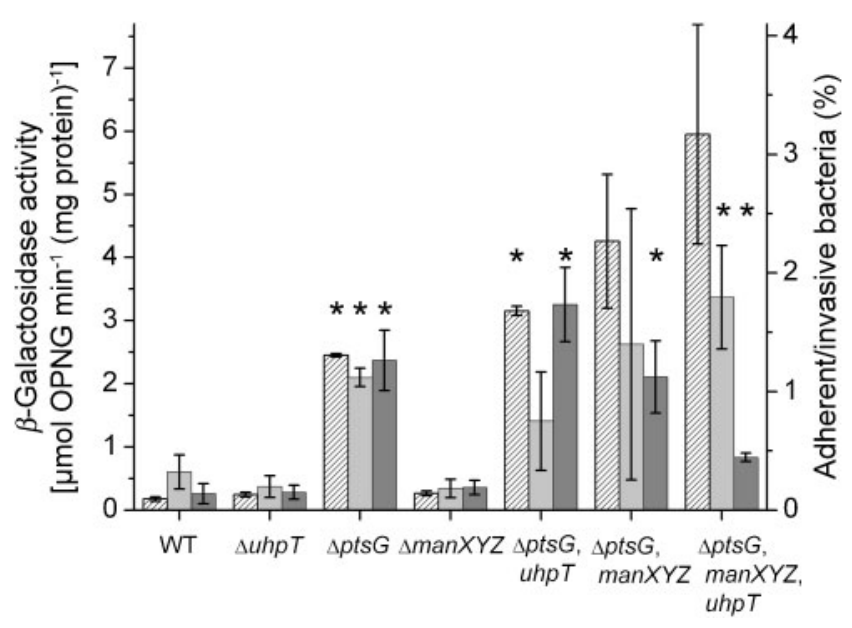

Fig. 4. Adhesion (light grey bars) and invasiveness (dark grey bars) of EIEC 4608-58 WT strain and mutants determined with Caco- 2 cells (for details see Methods). The numbers on the righthand $y$-axis represent the percentage of adherent or internalized bacteria relative to the total number of bacteria used for infection $\left(3 \times 10^{6}\right.$ c.f.u.). The $\beta$-galactosidase activity (left-hand $y$-axis; hatched bars) was also measured (after induction with lactose for $2 \mathrm{~h}$ ) to monitor the state of CCR of the WT and the carbohydrate uptake mutants. ${ }^{*} P<0.05$.

To determine the intracellular replication efficiency of the mutants in comparison to the wild-type strains, the numbers of bacteria used for infecting Caco-2 cells (90\% confluent cell layer) were adjusted according to their adhesion/invasion values (Fig. 4; Table 3) to reduce the intracellular bacterial count of the more invasive strains at the beginning of the intracellular growth period. Internalization by the Caco-2 cells was performed with bacteria resuspended in RPMI medium with and without $10 \%$ FCS, as described in Methods. Intracellular bacterial growth was monitored over a time period of $8 \mathrm{~h}$ p.i.. After
8 h replication, the EIEC strains reached a stationary phase but no apoptosis of the infected cells occurred. Growth of Stm 14028s had not yet reached stationary phase at this time point but replicated considerably more slowly after 8 h p.i.

When the infection was carried out in RPMI medium in the presence of $10 \%$ FCS, the EIEC 4608-58 wild-type as well as the $\Delta u h p T$ and $\triangle m a n X Y Z$ mutants replicated with mean generation times of $47 \pm 8$ min (shown in Fig. 5a for the wild-type strain). The $\Delta p t s G, \Delta p t s G, \operatorname{manXYZ}$ and $\Delta p t s G, u h p T$ mutants replicated at wild-type level until $3 \mathrm{~h}$ p.i., but their generation times dropped significantly in the next $3 \mathrm{~h}$ (shown in Fig. 5a for $\Delta p t s G$ ) compared with those of the wild-type strain $(77 \pm 12$ min versus $53 \pm 6 \mathrm{~min})$. The $\Delta p t s G, \operatorname{man} X Y Z, u h p T$ mutant showed a very low generation time $(215 \pm 36 \mathrm{~min})$ under these conditions (Fig. 5a). However, when the internalization of the EIEC 4608-58 wild-type and the mutants was carried out in FCSfree RPMI medium, the generation time of most mutants resembled that of the wild-type strain more, and even the $\Delta p t s G, \operatorname{manXYZ}, u h p T$ mutant replicated only slightly more slowly than the wild-type strain (Fig. 5b).

The EIEC HN280 strain and most of its mutants multiplied in Caco- 2 cells until $6 \mathrm{~h}$ p.i. with similar generation times $(55 \pm 3 \mathrm{~min})$ regardless of whether the internalization occurred in FCS-free or FCS-containing RPMI medium (Fig. $5 c, d$ ). Only the $\Delta p t s G, \operatorname{man} X Y Z$ and $\Delta p t s G$, manXYZ, uhpT mutants showed reduced intracellular generation times $(70 \pm 9 \mathrm{~min})$ that hardly changed in the absence of FCS (Fig. 5c, d).

The $\Delta u h p T, \Delta$ manXYZ and $\Delta g l k$ mutants of Stm $14028 \mathrm{~s}$ replicated in Caco-2 cells with the same intracellular doubling time as the wild-type strain (as shown in Fig. $5 \mathrm{f}$ for the $\Delta g l k$ mutant) while the $\Delta p t s G$ and even more the

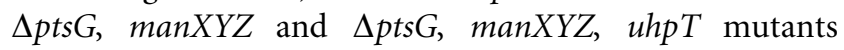
replicated more slowly (Fig. 5e). As expected, the generation times of Stm 14028s and the mutants (between

Table 3. Adhesion and invasion rates of EIEC HN280 and Stm 14028s wild-type strains and mutants obtained with Caco-2 cells

Values are given as percentage of adherent or internalized bacteria relative to the total number of bacteria used for infection $\left(3 \times 10^{6}\right.$ c.f.u. $)$. ND, Not determined.

\begin{tabular}{|c|c|c|c|}
\hline & \multicolumn{2}{|c|}{ EIEC HN280 } & \multirow[t]{2}{*}{ Stm $14028 \mathrm{~s}$ invasion (\%) } \\
\hline & Adhesion (\%) & Invasion (\%) & \\
\hline$\Delta u h p T$ & $2.64 \pm 0.62$ & $1.19 \pm 0.64$ & $2.09 \pm 1.21$ \\
\hline$\Delta p t s G$ & $2.23 \pm 1.12$ & $1.19 \pm 0.59$ & $1.73 \pm 0.74$ \\
\hline$\Delta \operatorname{manXYZ}$ & $2.63 \pm 0.48$ & $1.36 \pm 0.72$ & $\mathrm{ND}$ \\
\hline$\Delta p t s G, \operatorname{man} X Y Z$ & $0.13 \pm 0.03^{*}$ & $0.22 \pm 0.07^{\star}$ & $\mathrm{ND}$ \\
\hline$\Delta p t s G, \operatorname{man} X Y Z, u h p T$ & $0.63 \pm 0.10^{*}$ & $0.07 \pm 0.02^{\star}$ & $1.80 \pm 0.86$ \\
\hline
\end{tabular}

${ }^{\star} P<0.05$. 

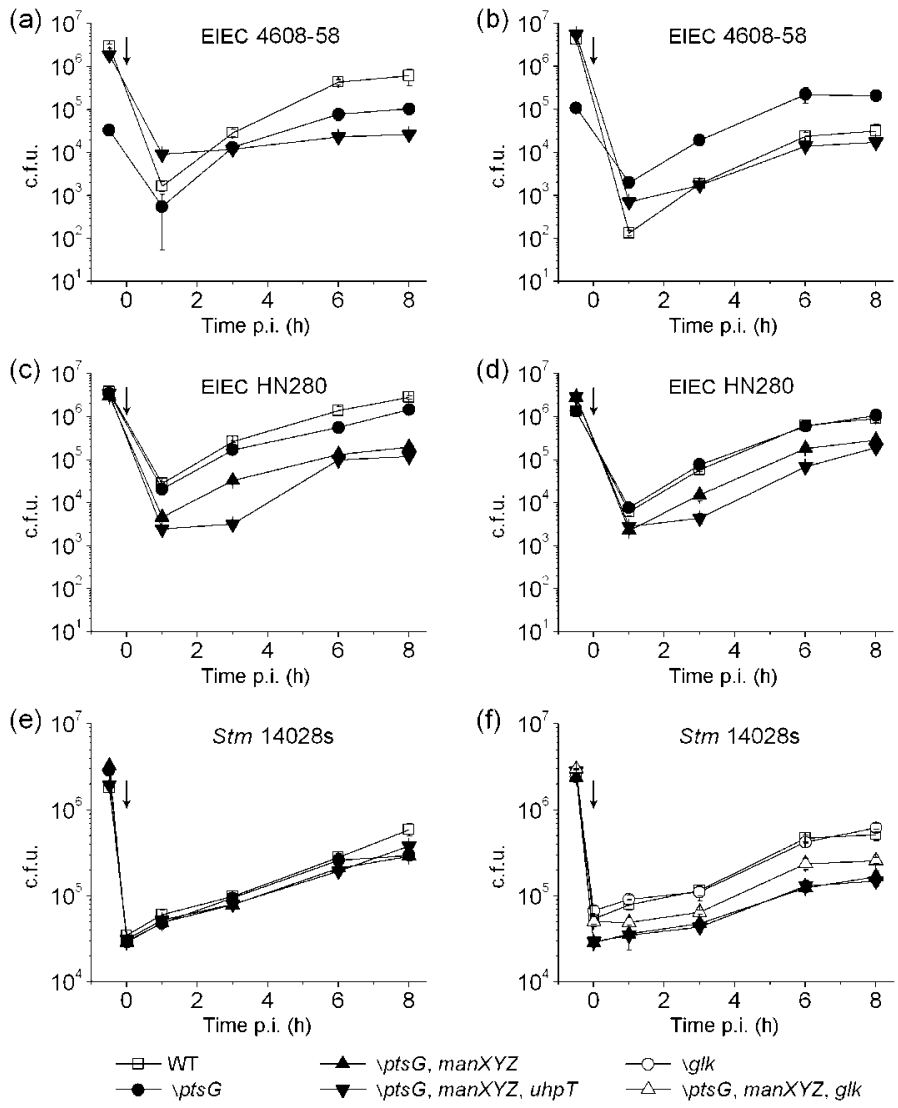

Fig. 5. Intracellular growth of EIEC 4608-58 (a, b), EIEC HN280 (c, d) and Stm 14028s (e, f) WT and their Glc- and/or Glc6P-uptake mutants in Caco-2 cells. Internalization was carried out in the presence $(a, c, e, f)$ or absence $(b, d)$ of $10 \%$ FCS with different amounts of bacteria as described in Methods to reduce the intracellular bacterial counts (first time point p.i.) of the highly invasive $\Delta p t s G$ mutants. Time point $\mathrm{Oh}$ p.i. (indicated by arrows) marks the addition of gentamicin. Each experiment was performed three times in triplicate (mean $\pm S D$ shown); a representative experiment is shown.
150 and $170 \mathrm{~min}$ ) were considerably longer than those observed with the EIEC wild-type strains and most of their mutants. Even the $\Delta p t s G, \operatorname{manXYZ}$, glk mutant was still able to replicate in Caco-2 cells with a similar generation time to the $\Delta p t s G, \operatorname{manXYZ}, u h p T$ (Fig. 5f). These latter data were unexpected since a similar $\triangle p t s G, \operatorname{manXYZ,glk}$ mutant of strain $S$. Typhimurium 4/74 showed a much stronger growth inhibition when replicating in RAW 264.7 macrophages (Bowden et al., 2009).

\section{DISCUSSION}

Glucose (Glc), mannose (Man) and glucose 6-phosphate (Glc6P) are the preferred carbon sources for growth of $E$. coli and the entire family of Enterobacteriaceae. These carbon sources may be also encountered within mammalian host cells by those family members that are able to invade and actively replicate in these host cells, mainly Salmonella spp. and Shigella spp. (as well as the closely related EIEC).

The transport of these carbohydrates has been extensively studied in the model enteric bacteria E. coli K-12 and S. Typhimurium LT2 where several PTS and non-PTS transporters for glucose were identified (Death \& Ferenci, 1993; Henderson et al., 1977; Postma et al., 1993). PtsG/Crr is the major transporter for Glc, but ManXYZ, primarily a Man PTS (Erni \& Zanolari, 1985; Erni et al., 1987), can also efficiently transport Glc in both species. The major transporter for Glc6P is the $\mathrm{P}_{\mathrm{i}} / \mathrm{Glc} 6 \mathrm{P}$ antiporter UhpT (Island et al., 1992).

As expected, deletions of $p t s G$ and manXYZ in E. coli $\mathrm{K}-12$ abolish growth entirely when the $\triangle p t s G$, manXYZ mutant is cultured in RPMI medium with low $(2 \mathrm{mM})$ or high (10 mM) concentrations of Glc or Man as carbon source, and the E. coli K-12 $\Delta u h p T$ mutant is unable to multiply in RPMI with Glc6P. The well-defined RPMI medium is utilized in this study for in vitro growth, since uptake and replication of facultative intracellular bacteria in mammalian cells (including those reported here) is most frequently carried out in this medium.

The results obtained with the facultative intracellular enteric bacteria, two enteroinvasive E. coli strains (EIEC 4608-58 and EIEC HN280), one S. Typhimurium strain (Stm 14028s) and the corresponding mutants of these wildtype strains show, however, a more differentiated picture than E. coli K-12 with respect to Glc and Glc6P transport.

Deletion of $p t s G$ alone leads to strong growth inhibition in the presence of Glc as sole carbon source in EIEC HN280 only, which is comparable to, but not as evident as, the inhibition of E. coli K-12; however, it has relatively little effect on growth of EIEC 4608-58 and Stm 14028s, even at low Glc concentration $(2 \mathrm{mM})$. This Glc concentration can be expected in the cytosol of Caco- 2 cells where the two 
EIEC strains replicate, but the Glc concentration in the SCV where Stm 14028s multiplies is basically unknown under the applied culture conditions.

While deletion of $p t s G$ and manXYZ inhibits in vitro growth at low Glc concentration in both EIEC strains, the $\Delta p t s G, \operatorname{manXYZ}$ mutant of Stm 14028s shows still substantial growth under these conditions and reaches the same cell density as the wild-type strain in the stationary growth phase, suggesting that other Glc transporters, possibly the non-PTS permeases GalP and MglABC (Death \& Ferenci, 1993; Postma, 1977), may function as efficient Glc transporters in Stm 14028s.

Growth differences between the two EIEC isolates and E. coli $\mathrm{K}-12$ are especially remarkable with Glc6P as carbon source. While the $\Delta u h p T$ mutant of EIEC HN280, similar to the corresponding E. coli $\mathrm{K}-12$ mutant, is unable to grow in the presence of Glc6P, the $\Delta u h p T$ mutant of EIEC 460858 can still grow with about a doubled generation time and reaches the same cell density as the wild-type strain in the stationary phase. Our results show that this growth capacity of the $\Delta u h p T$ mutant is not caused by a second uhpT gene. Transport of Glc6P by UhpC, which may occur in E. coli $\mathrm{K}-12$ in the absence of UhpT (Schwoppe et al., 2002, 2003), or by other UhpT-homologous transporters, like the glycerol-3-phosphate antiporter GlpT, or the putative PEP transporter PgtP (Johnson et al., 2007; Welch et al., 2002), can be ruled out too, since deletion of these genes does not alter the growth properties of the EIEC 4608-58 wild-type strain or the $u h p T$ mutant in the presence of Glc6P. These data thus suggest that EIEC 460858 may possess another type of Glc6P transporter in addition to UhpT.

Adhesion of all three intracellular pathogens to Caco-2 cells correlates with their internalization by Caco- 2 cells. Similar adhesion and invasion efficiencies are observed for Stm 14028s and EIEC HN280, while those of EIEC 4608-58 are more than fivefold lower. Loss of Glc and Glc6P transport does not significantly affect adhesion and invasiveness of Stm 14028s, but leads to significant variations in both properties of the EIEC strains.

Deletion of $p t s G$ (but not of manXYZ or uhpT) results in a more than fivefold increased adherence and invasiveness of EIEC 4608-58, but not of EIEC HN280. Although the deletion of $p t s G$ has only a moderate effect on Glcmediated growth in vitro (Fig. 1a, b), it seems to lead to partial relaxation of CCR as indicated by the increased $\beta$ galactosidase activity of the $\Delta p t s G$ mutant. Expression of the IpaBC complex, mainly responsible for invasion of Shigella and EIEC (Cossart \& Sansonetti, 2004) is not under CCR control (Dagberg \& Uhlin, 1992), suggesting that an additional, CCR-regulated factor(s) may stimulate adhesion and subsequently invasion of EIEC 4608-58 to Caco-2 cells.

While the deletion of $p t s G$ or manXYZ in EIEC HN280 has no effect on adhesion and invasion, the deletion of both pts $G$ and manXYZ leads to a strong decrease of both properties of this strain. The reason for this decrease is presently unknown. A possible explanation might be an impaired synthesis and/or translocation of effector molecules (via the type III secretion system), necessary for adhesion/invasion (Cossart \& Sansonetti, 2004; Lafont \& van der Goot, 2005; Scherer et al., 1997). The better adherence of the corresponding EIEC 4608-58 mutant might compensate for this impairment.

Although the $\Delta p t s G$, manXYZ mutant of EIEC HN280 is unable to grow with Glc as sole carbon source in vitro, this

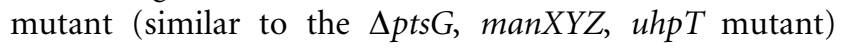
replicates only slightly more slowly in Caco-2 cells than the wild-type strain (within the $8 \mathrm{~h}$ period of infection where intracellular growth was monitored and where no apoptosis of the infected cells occurred, the wild-type strain underwent eight, and the mutants six, cell divisions).

A similar picture is observed with Stm 14028s: here, the wild-type strain (replicating more slowly in the SCV) underwent four and the mutants, including the $\Delta p t s G$, manXYZ, glk mutant, underwent three cell divisions, although these mutants (in particular the $\Delta p t s G$, manXYZ, glk mutant) showed drastically reduced growth rates in vitro in the presence of low (2 mM) Glc and Glc6P, respectively.

The $\Delta p t s G$ mutant of EIEC 4608-58 exhibited only a moderate reduction in viable bacterial counts in Caco-2 cells compared with the wild-type strain when the bacteria were treated with $10 \%$ FCS prior to infection, but the $\Delta p t s G, \operatorname{man} X Y Z, u h p T$ mutant showed a strong reduction. This reduction seems to have been caused, however, mainly by increased killing of the FCS-treated mutant bacteria, since the untreated bacteria showed much better growth in Caco-2 cells, closely resembling that of the corresponding EIEC HN280 mutant. A higher fragility of the $\Delta p t s G$, manXYZ, uhpT mutant of EIEC 4608-58 is also indicated by the increased autolysis in the stationary phase during extracellular growth.

These data show that intracellular growth of the two EIEC strains and the $S$. Typhimurium strain analysed in this study does not depend exclusively on Glc (or Glc6P) when replicating in Caco-2 cells. Indeed, an in-depth analysis of the intracellular carbon metabolism of the two EIEC strains and Stm 14028 s by ${ }^{13} \mathrm{C}$-isotopologue analysis with uniformly labelled $\left[{ }^{13} \mathrm{C}\right]$ glucose revealed that Glc (but not Glc6P) is the preferred carbon source for EIEC HN280 and Stm 14028s when replicating in Caco-2 cells. But, both strains can readily switch to $\mathrm{C}_{3}$-carbon sources when Glc becomes unavailable (A. Götz and other authors, unpublished data). Thus, the relatively minor reduction of intracellular growth in Caco-2 cells of mutants lacking the ability to utilize Glc, compared with the strong growth inhibition of these mutants in RPMI medium with Glc probably reflects the capacity of the mutants to grow intracellularly on alternative carbon substrates in the absence of Glc. There may be, however, bacterial strain- 
and/or host cell-specific differences with respect to the dependency on Glc for intracellular growth of $S$. Typhimurium. Recently, Bowden et al. (2009) reported

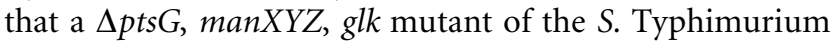
4/74 strain when replicating in RAW 264.7 macrophages exhibits a much stronger growth inhibition in these macrophages (Bowden et al., 2009) than the corresponding mutant of strain Stm 14028s in Caco-2 cells analysed in this study.

Interestingly, neither the results reported here nor the ${ }^{13} \mathrm{C}$ isotopologue analysis (A. Götz and other authors, unpublished data) show a significant contribution of Glc6P to intracellular replication of the EIEC strains (replicating in the cytosol) or S. Typhimurium (replicating in the SCV), although transcription of the uhpT gene is induced under these conditions (Hautefort et al., 2008; Lucchini et al., 2005). Possibly, the observed transcriptional uhpT induction is simply caused by a decreased CCR of the intracellular growing bacteria due to the lower Glc concentration in the host cells compared with the extracellular medium, but this has no major impact on the intracellular carbon metabolism of these enteric bacteria.

\section{ACKNOWLEDGEMENTS}

This work was supported by a grant from the German Research Foundation (DFG) (SFB479-B1) and the Network of Excellence 'EuroPathoGenomics' (NoE EPG). A. G. received a PhD grant from the International DFG Research Training Group 1141 Würzburg/ Nice (GCWN) and the Franco-German University (ED-31-04).

\section{REFERENCES}

Bell, K. S., Sebaihia, M., Pritchard, L., Holden, M. T., Hyman, L. J., Holeva, M. C., Thomson, N. R., Bentley, S. D., Churcher, L. J. \& other authors (2004). Genome sequence of the enterobacterial phytopathogen Erwinia carotovora subsp. atroseptica and characterization of virulence factors. Proc Natl Acad Sci U S A 101, 11105-11110.

Beuzón, C. R., Meresse, S., Unsworth, K. E., Ruiz-Albert, J., Garvis, S., Waterman, S. R., Ryder, T. A., Boucrot, E. \& Holden, D. W. (2000). Salmonella maintains the integrity of its intracellular vacuole through the action of SifA. EMBO J 19, 3235-3249.

Beuzón, C. R., Salcedo, S. P. \& Holden, D. W. (2002). Growth and killing of a Salmonella enterica serovar Typhimurium sifA mutant strain in the cytosol of different host cell lines. Microbiology 148, 2705-2715.

Bolivar, F., Rodriguez, R. L., Greene, P. J., Betlach, M. C., Heynker, H. L., Boyer, H. W., Crosa, J. H. \& Falkow, S. (1992). Construction and characterization of new cloning vehicles. II. A multipurpose cloning system. 1977. Biotechnology 24, 153-171.

Bowden, S. D., Rowley, G., Hinton, J. C. \& Thompson, A. (2009). Glucose and glycolysis are required for the successful infection of macrophages and mice by Salmonella enterica serovar Typhimurium. Infect Immun 77, 3117-3126.

Brumell, J. H. \& Grinstein, S. (2004). Salmonella redirects phagosomal maturation. Curr Opin Microbiol 7, 78-84.

Clermont, O., Bonacorsi, S. \& Bingen, E. (2000). Rapid and simple determination of the Escherichia coli phylogenetic group. Appl Environ Microbiol 66, 4555-4558.
Cossart, P. \& Sansonetti, P. J. (2004). Bacterial invasion: the paradigms of enteroinvasive pathogens. Science 304, 242-248.

Covarrubias, L., Cervantes, L., Covarrubias, A., Soberon, X., Vichido, I., Blanco, A., Kupersztoch-Portnoy, Y. M. \& Bolivar, F. (1981). Construction and characterization of new cloning vehicles. V. Mobilization and coding properties of pBR322 and several deletion derivatives including pBR327 and pBR328. Gene 13, 25-35.

Dagberg, B. \& Uhlin, B. E. (1992). Regulation of virulence-associated plasmid genes in enteroinvasive Escherichia coli. J Bacteriol 174, 76067612.

Datsenko, K. A. \& Wanner, B. L. (2000). One-step inactivation of chromosomal genes in Escherichia coli K-12 using PCR products. Proc Natl Acad Sci U S A 97, 6640-6645.

Death, A. \& Ferenci, T. (1993). The importance of the bindingprotein-dependent $\mathrm{Mgl}$ system to the transport of glucose in Escherichia coli growing on low sugar concentrations. Res Microbiol 144, 529-537.

Erni, B. \& Zanolari, B. (1985). The mannose-permease of the bacterial phosphotransferase system. Gene cloning and purification of the enzyme IIMan/IIIMan complex of Escherichia coli. J Biol Chem 260, 15495-15503.

Erni, B., Zanolari, B. \& Kocher, H. P. (1987). The mannose permease of Escherichia coli consists of three different proteins. Amino acid sequence and function in sugar transport, sugar phosphorylation, and penetration of phage lambda DNA. J Biol Chem 262, 5238-5247.

Eylert, E., Schar, J., Mertins, S., Stoll, R., Bacher, A., Goebel, W. \& Eisenreich, W. (2008). Carbon metabolism of Listeria monocytogenes growing inside macrophages. Mol Microbiol 69, 1008-1017.

Hautefort, I., Thompson, A., Eriksson-Ygberg, S., Parker, M. L., Lucchini, S., Danino, V., Bongaerts, R. J., Ahmad, N., Rhen, M. \& Hinton, J. C. (2008). During infection of epithelial cells Salmonella enterica serovar Typhimurium undergoes a time-dependent transcriptional adaptation that results in simultaneous expression of three type 3 secretion systems. Cell Microbiol 10, 958-984.

Henderson, P. J., Giddens, R. A. \& Jones-Mortimer, M. C. (1977). Transport of galactose, glucose and their molecular analogues by Escherichia coli K12. Biochem J 162, 309-320.

Island, M. D., Wei, B. Y. \& Kadner, R. J. (1992). Structure and function of the uhp genes for the sugar phosphate transport system in Escherichia coli and Salmonella typhimurium. J Bacteriol 174, 27542762.

Jin, Q., Yuan, Z., Xu, J., Wang, Y., Shen, Y., Lu, W., Wang, J., Liu, H., Yang, J. \& other authors (2002). Genome sequence of Shigella flexneri 2a: insights into pathogenicity through comparison with genomes of Escherichia coli K12 and O157. Nucleic Acids Res 30, 4432-4441.

Johnson, T. J., Kariyawasam, S., Wannemuehler, Y., Mangiamele, P., Johnson, S. J., Doetkott, C., Skyberg, J. A., Lynne, A. M., Johnson, J. R. \& Nolan, L. K. (2007). The genome sequence of avian pathogenic Escherichia coli strain $\mathrm{O} 1: \mathrm{K} 1: \mathrm{H} 7$ shares strong similarities with human extraintestinal pathogenic E. coli genomes. J Bacteriol 189, 3228-3236.

Klumpp, J. \& Fuchs, T. M. (2007). Identification of novel genes in genomic islands that contribute to Salmonella typhimurium replication in macrophages. Microbiology 153, 1207-1220.

Lafont, F. \& van der Goot, F. G. (2005). Bacterial invasion via lipid rafts. Cell Microbiol 7, 613-620.

Lucchini, S., Liu, H., Jin, Q., Hinton, J. C. \& Yu, J. (2005). Transcriptional adaptation of Shigella flexneri during infection of macrophages and epithelial cells: insights into the strategies of a cytosolic bacterial pathogen. Infect Immun 73, 88-102.

McClelland, M., Sanderson, K. E., Spieth, J., Clifton, S. W., Latreille, P., Courtney, L., Porwollik, S., Ali, J., Dante, M. \& other authors 
(2001). Complete genome sequence of Salmonella enterica serovar Typhimurium LT2. Nature 413, 852-856.

Meyer, D., Schneider-Fresenius, C., Horlacher, R., Peist, R. \& Boos, W. (1997). Molecular characterization of glucokinase from Escherichia coli K-12. J Bacteriol 179, 1298-1306.

Nicoletti, M., Superti, F., Conti, C., Calconi, A. \& Zagaglia, C. (1988). Virulence factors of lactose-negative Escherichia coli strains isolated from children with diarrhea in Somalia. J Clin Microbiol 26, 524-529.

Phalipon, A. \& Sansonetti, P. J. (2007). Shigella's ways of manipulating the host intestinal innate and adaptive immune system: a tool box for survival? Immunol Cell Biol 85, 119-129.

Postma, P. W. (1977). Galactose transport in Salmonella typhimurium. J Bacteriol 129, 630-639.

Postma, P. W., Lengeler, J. W. \& Jacobson, G. R. (1993). Phosphoenolpyruvate: carbohydrate phosphotransferase systems of bacteria. Microbiol Rev 57, 543-594.

Sansonetti, P. J., d'Hauteville, H., Formal, S. B. \& Toucas, M. (1982). Plasmid-mediated invasiveness of "Shigella-like" Escherichia coli. Ann Microbiol (Paris) 133, 351-355.

Scherer, C. A., Hantman, M. J. \& Miller, S. I. (1997). Salmonella invasion and delivery of protein effectors to mammalian cell cytoplasm. Trends Microbiol 5, 127-129.
Schwoppe, C., Winkler, H. H. \& Neuhaus, H. E. (2002). Properties of the glucose-6-phosphate transporter from Chlamydia pneumoniae (HPTcp) and the glucose-6-phosphate sensor from Escherichia coli (UhpC). J Bacteriol 184, 2108-2115.

Schwoppe, C., Winkler, H. H. \& Neuhaus, H. E. (2003). Connection of transport and sensing by UhpC, the sensor for external glucose-6phosphate in Escherichia coli. Eur J Biochem 270, 1450-1457.

Stock, J. B., Waygood, E. B., Meadow, N. D., Postma, P. W. \& Roseman, S. (1982). Sugar transport by the bacterial phosphotransferase system. The glucose receptors of the Salmonella typhimurium phosphotransferase system. J Biol Chem 257, 14543-14552.

Vazquez-Torres, A. \& Fang, F. C. (2000). Cellular routes of invasion by enteropathogens. Curr Opin Microbiol 3, 54-59.

Verhamme, D. T., Postma, P. W., Crielaard, W. \& Hellingwerf, K. J. (2002). Cooperativity in signal transfer through the Uhp system of Escherichia coli. J Bacteriol 184, 4205-4210.

Welch, R. A., Burland, V., Plunkett, G., III, Redford, P., Roesch, P., Rasko, D., Buckles, E. L., Liou, S. R., Boutin, A. \& other authors (2002). Extensive mosaic structure revealed by the complete genome sequence of uropathogenic Escherichia coli. Proc Natl Acad Sci U S A 99, 17020-17024.

Edited by: R. J. Maier 